\title{
CORRESPONDENCE
}

\section{Radicals in the church}

\section{To the Editors:}

Public health is seriously threatened by exposure to ambient and indoor particulate matter (PM). Epidemiological studies have demonstrated that long-term exposure is associated with lung cancer and other pulmonary diseases [1]. In vitro studies have demonstrated the involvement of polycyclic aromatic hydrocarbons (PAH), inflammation and oxidative stress in these adverse health effects [2-4]. As free radicals are also known to play a crucial role in these processes, we developed an electron spin resonance (ESR)based methodology to quantify the radical-generating capacity of PM. We applied this methodology in order to evaluate the effect of burning candles and incense, known sources of indoor air PM [5], on the radical-generating capacity of PM in a Roman Catholic church (Onze Lieve Vrouwe Basiliek, Maastricht, The Netherlands).

PM passing through a size-selective inlet with a $50 \%$ efficiency cut-off at a $10-\mu \mathrm{m}$ aerodynamic diameter (PM10) was sampled in a small chapel before and after $9 \mathrm{~h}$ of continuous candle burning (the normal daily practice). Additionally, in a large basilica, PM10 was sampled before and after a simulated service with incense burning. Radicalgenerating capacity and total PAH concentrations were analysed and compared to those of PM10 from high-traffic locations. Free-radical formation was measured by placing the filters directly into the ESR apparatus, after adding the spin trap 5,5-dimethyl-1-pyrroline- $N$-oxide.

It was found that PM10 concentrations before candle/ incense burning are three-fold higher as compared with the outdoor values (table 1), and clearly exceed the 24-h average European Union standard of $50 \mu \mathrm{g} \cdot \mathrm{m}^{-3}$. Moreover, incense and candle burning were found to increase PM10 concentrations up to levels exceeding $1,000 \mu \mathrm{g} \cdot \mathrm{m}^{-3}$. The average oxygen radical-generating capacity of PM10 from high-traffic locations was remarkably lower as compared with that of PM10 sampled before and after candle or incense burning. The postservice measurements in the church show that the burning of incense generates an additional ESR signal that is typical for a carbon-centred radical, whereas oxygen-radical formation decreases concomitantly. This suggests that the interaction between oxygen free radicals and other organic substances present in incense-derived PM results in the formation of this other type of radical. Furthermore, a signal of an unidentified free radical is found after burning incense and, even more pronounced, after burning candles in the chapel. A search in the US National Institute of Environmental Health Sciences (NIEHS) spin trap database [6] did not link this ESR signal to any known type of free radical. Pre-service PAH levels in both church and chapel were higher as compared with the outdoor measurements, and increased by a factor of four and 10 after burning incense and candles, respectively.

In view of the exceptionally high particulate matter passing through a size-selective inlet with a $50 \%$ efficiency cut-off at a $10-\mu \mathrm{m}$ aerodynamic diameter and high polycyclic aromatic hydrocarbons levels found in this church, combined with a high radical-generating capacity, it cannot be excluded that regular exposure to candle- or incense-derived particulate matter results in increased risk of lung cancer or other pulmonary diseases. Further research is needed to characterise the genotoxic potential of the unidentified radicals and to evaluate the actual health risk associated with exposure to this mix of free radicals and carcinogenic polycyclic aromatic hydrocarbons.

T.M.C.M. de Kok* , J.G.F. Hogervorst ${ }^{\#}$, J.C.S. Kleinjans*, J.J. Briedé*

Depts of *Health Risk Analysis and Toxicology, and ${ }^{\#}$ General Practice, Maastricht University, Maastricht, The Netherlands.

\section{References}

1. Colburn KA, Johnson PR. Public health. Air pollution concerns not changed by S-PLUS flaw. Science 2003; 299: 665-666.

2. Reed M, Monske M, Lauer F, Meserole S, Born J, Burchiel $\mathrm{S}$. Benzo[a]pyrene diones are produced by photochemical and enzymatic oxidation and induce concentration-dependent decrease in the proliferation state of human pulmonary epithelila cells. J Toxicol Environ Health A 2003; 66: 11891205.

3. Dellinger B, Pryer WA, Cueto R, Squadrito GL, Hegde V, Deutsch WA. Role of free radicals in the toxicity of airborne fine particulate matter. Chem Res Toxicol 2001; 14: 1371-1377.

Table 1.-PM10 concentrations, radical-generating capacity and polycyclic aromatic hydrocarbons (PAH) concentrations

\begin{tabular}{lccccc}
\hline & PM10 $\mu \mathrm{g} \cdot \mathrm{m}^{-3}$ & $\begin{array}{c}\text { Oxygen } \\
\text { radicals }^{\#} \mathrm{AU} \cdot \mathrm{m}^{-3}\end{array}$ & $\begin{array}{c}\text { Carbon-centred } \\
\text { radicals }^{\#} \mathrm{AU} \cdot \mathrm{m}^{-3}\end{array}$ & $\begin{array}{c}\text { Unidentified } \\
\text { radicals }^{\#} \mathrm{AU} \cdot \mathrm{m}^{-3}\end{array}$ & $\begin{array}{c}\text { Total PAH } \\
\mathrm{concentration}^{-} \mathrm{ng} \cdot \mathrm{m}^{-3}\end{array}$ \\
\hline Church pre-service & 163 & 52.3 & 0 & 0 & 16.4 \\
Church post-service & 658 & 19.8 & 12.5 & 3.9 & 0 \\
Chapel before candle burning & 233 & 53.7 & 0 & 45.6 & 11.2 \\
Chapel after candle burning & 1013 & 60.8 & 0 & 0 & 110.0 \\
High-traffic outdoor locations $^{+}$ & 53 & 6.3 & 0 & 7.4 \\
\hline
\end{tabular}

PM10: particulate matter passing through a size-selective inlet with a $50 \%$ efficiency cut-off at a $10-\mu \mathrm{m}$ aerodynamic diameter. ${ }^{\#}$ : radical-generating

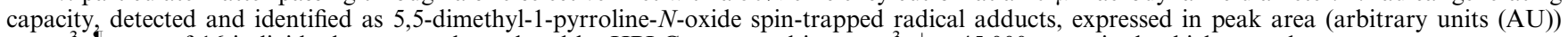
per $\mathrm{m}^{3}$; : sum of 16 individual compounds analysed by HPLC, expressed in $\mathrm{ng} \cdot \mathrm{m}^{-3} ;{ }^{+}:>45,000$ motorised vehicles per day. 
4. Roberts ES, Richards JH, Jaskot R, Dreher KL. Oxidative stress mediates air pollution particle-induced acute lung injury and molecular pathology. Inhal Toxicol 2003; 15: 1327-1346.

5. Lung SC, Kao MC, Hu SC. Contribution of incense burning to indoor PM10 and particle-bound polycyclic aromatic hydrocarbons under two ventilation conditions. Indoor Air 2003; 13: 194-199.

6. US National Institute of Environmental Health Services (NIEHS). Spin trap database. dir-apps.niehs.nih.gov/stdb/ index.cfm. Date last updated: September 23 2002. Date last accessed: August 312004.

\section{Combination therapy with maintenance budesonide and formoterol in COPD}

\section{To the Editors:}

CALVERLEY et al. [1] provide further evidence for combination therapy with inhaled corticosteroids and long-acting $\beta$-agonists in severe chronic obstructive pulmonary disease (COPD) as maintenance therapy. In addition, a previous study, also confirming such benefit, showed an advantage for monotherapy with fluticasone in reducing exacerbations [2]. The study by CALVERLEY et al. [1] did not show a benefit for budesonide monotherapy in exacerbation reductions. Does monotherapy with inhaled steroids reduce exacerbations in severe COPD?

The conclusion that "additional clinical benefit when combined in a single inhaler" would surely be further strengthened by assessing the effectiveness of the fixed-dose single inhaler combination against the same drugs in separate inhalers? As there are sound cellular reasons for combining these two classes of drug [3], would there not be a potential advantage in the use of these two drugs as separate inhalers to allow greater dose flexibility, although this is of greater relevance in asthma? Or, if fixed-dose combinations are superior to separate inhalers taken together, then would this also be an important finding to favour the former?

\section{A.R.L. Medford}

Dept of Respiratory Medicine, Southmead Hospital, Bristol, UK.

\section{References}

1. Calverley PM, Boonsawat W, Cseke Z, Zhong N, Peterson S, Olsson H. Maintenance therapy with budesonide and formoterol in chronic obstructive pulmonary disease. Eur Respir J 2003; 22: 912-919.

2. Calverley P, Pauwels R, Vestbo J, et al. Combined salmeterol and fluticasone in the treatment of chronic obstructive pulmonary disease: a randomised controlled trial. Lancet 2003; 361: 449-456.

3. Barnes PJ. Scientific rationale for inhaled combination therapy with long-acting beta2-agonists and corticosteroids. Eur Respir J 2002; 19: 182-191.

DOI: $10.1183 / 09031936.04 .00081604$

\section{From the author:}

We are grateful for A.R.L. Medford's interest in our study [1]. The patients in our trial had relatively severe chronic obstructive pulmonary disease (COPD; mean forced expiratory volume in one second (FEV1) 36\% predicted), as did those in a companion study of the same treatment that used a different trial design [2]. In both trials, budesonide via a dry powder reservoir delivery system was less effective in preventing exacerbations than fluticisone delivered in a slightly higher dose in the TRial of Inhaled STeroids ANd long-acting $\beta$ agonists (TRISTAN) of patients with a mean FEV1 44\% pred [3]. These disparities may reflect differences in the dose given, the delivery system or the effectiveness of inhaled corticosteroids in more severe disease, and our data cannot resolve this point. However, a more recent analysis of the TRISTAN data set, which is currently being prepared for publication, suggests that the effect of the inhaled corticosteroid on exacerbation numbers was less marked in those patients with more severe disease, and this would be in keeping with the findings of our study. We were reassured to see that, in both trials, the budesonide-formoterol combination reduced exacerbation numbers significantly, despite the relatively limited impact of the inhaled corticosteroid given alone. The current guidance on the use of inhaled corticosteroids in COPD recommends that they should be added into maintenance bronchodilator therapy, which should ideally be provided by a long-acting inhaled bronchodilator [4], and the use of inhaled corticosteroid as monotherapy to prevent exacerbations is not recommended.

Our statement about the benefits of combining treatment in a single inhaler was strictly factual, as we were not in a position to conduct the proposed comparison of fixed doses versus the same drug given in separate inhalers. Clearly, this is of practical relevance, but, unfortunately, calculating the statistical power of a study that could conclusively establish a difference between such treatment interventions suggests that it would have to be a substantially larger study than any that have been reported so far. We agree that there are good reasons for combining long-acting $\beta$-agonists and an inhaled corticosteroid, but the data about dose flexibility in chronic obstructive pulmonary disease has not been explored. There may be some utility in delivering the drugs together in a fixed dose combination at the site of action, rather than potentially allowing for different patterns of airway deposition on individual inhaler actuations. Such concerns remain of theoretical interest, but are hard to test with our existing techniques and in representative populations of chronic obstructive pulmonary disease patients. There are certainly advantages of convenience and, potentially, of treatment adherence by giving both drugs together, but this will need to be established in future studies.

P.M.A. Calverley

Clinical Sciences Centre, University Hospital Aintree, Liverpool, UK. 